\title{
Unsung heroes of the scientific record deserve credit
}

\author{
Reviewers make an essential contribution to scientific progress; Nature Communications will now for- \\ mally acknowledge their role in published articles.
}

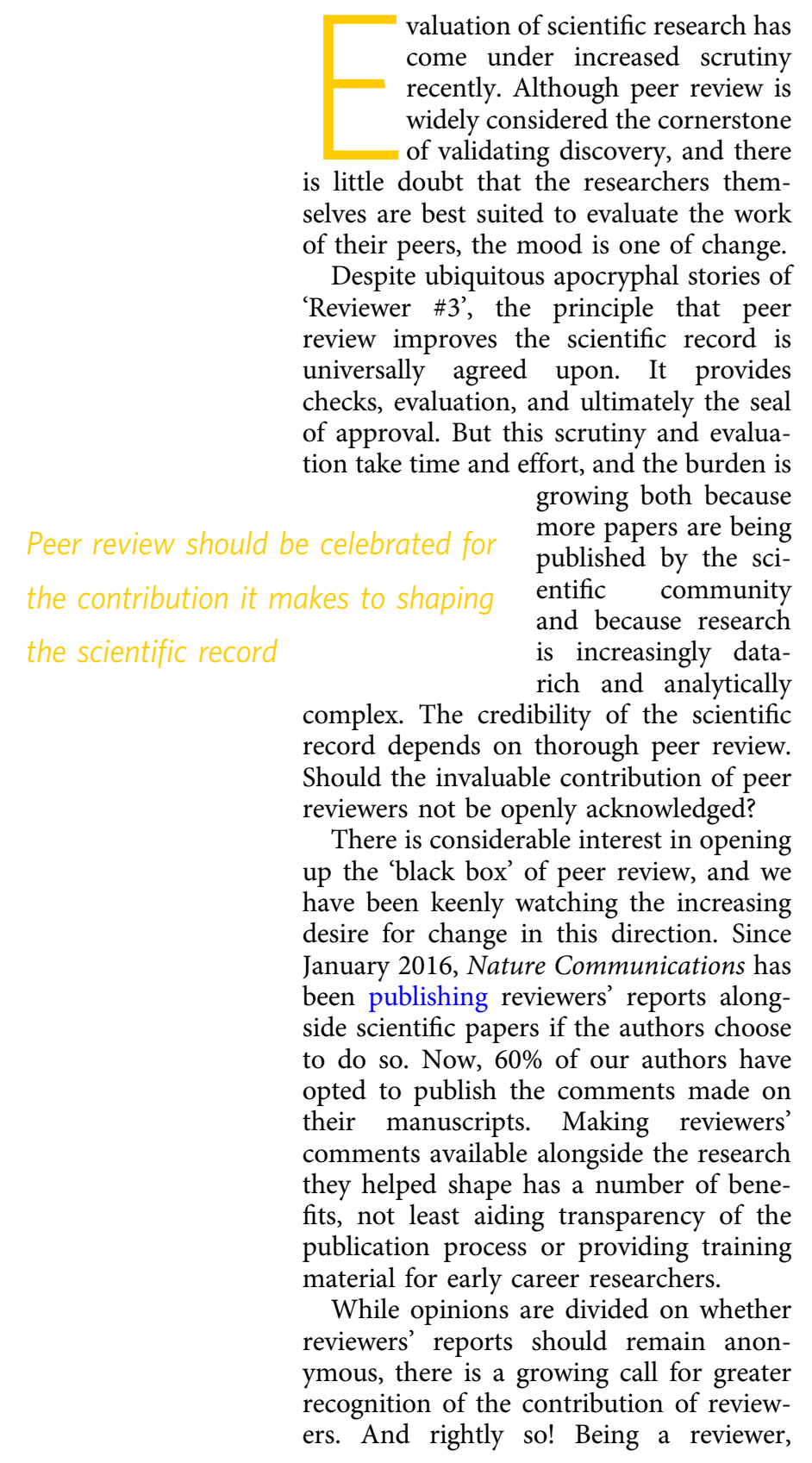

let alone a good, constructive reviewer, has unfortunately always been a peripheral consideration when it comes to promotion or funding applications. The emphasis has consistently been almost entirely on the research output in the form of authorship of scientific papers, even though being a scientist entails so much more.

Nature recently started a trial in which reviewers can be acknowledged by name in the publications they have helped shape. We are delighted to announce that we are now introducing this to Nature Communications. From today, reviewers will be asked when submitting their comments on a manuscript under consideration at Nature Communications if they would like to be named on the paper, should it be published. We will also be encouraging them to sign their comments to the authors, with the aim that, if the comments are published, they will receive full credit for their contribution to the work. Should a reviewer opt out of being named, we will acknowledge their contribution anonymously.

Peer review should be celebrated for the contribution it makes to shaping the scientific record. Being a reviewer entails a great deal of effort and responsibility, but often the anonymity of the peer review process prevents the appropriate attribution of credit and prestige. Increasingly, publishers and third-party services are finding ways to recognise the contribution of individual reviewers while abiding by the confidentiality policies of the journals, or lifting the anonymity veil altogether. At Nature Communications, we are keen to do our part in supporting this trend.

We are operating this as a trial and will report back on its success, and its operation with our existing transparent peer review scheme, within a year. We will also be collecting demographic information, on a 
voluntary basis, such as gender, country of affiliation, and career stage, from our reviewers so that we can meaningfully assess the impact and level of uptake of this trial. Further details can be found in a dedicated FAQ document.

Published online: 20 November 2018 cc) (i) Open Access This article is licensed under a Creative Commons Attribution 4.0 International License, which permits use, sharing, adaptation, distribution and reproduction in any medium or format, as long as you give appropriate credit to the original author(s) and the source, provide a link to the Creative Commons license, and indicate if changes were made. The images or other third party material in this article are included in the article's Creative Commons license, unless indicated otherwise in a credit line to the material. If material is not included in the article's Creative
Commons license and your intended use is not permitted by statutory regulation or exceeds the permitted use, you will need to obtain permission directly from the copyright holder. To view a copy of this license, visit http:// creativecommons.org/licenses/by/4.0/.

(C) Springer Nature Ltd 2018 